\title{
A Wideband End-Fire Conformal Vivaldi Antenna Array Mounted on a Dielectric Cone
}

\author{
Zengrui Li, ${ }^{1}$ Xiaole Kang, ${ }^{1}$ Jianxun Su, ${ }^{1}$ Qingxin Guo, \\ Yaoqing (Lamar) Yang, ${ }^{2}$ and Junhong Wang ${ }^{3}$ \\ ${ }^{1}$ School of Information Engineering, Communication University of China, Beijing 100024, China \\ ${ }^{2}$ Department of Electrical and Computer Engineering, University of Nebraska-Lincoln, Omaha, NE 68182, USA \\ ${ }^{3}$ Institute of Lightwave Technology, Beijing Jiaotong University, Beijing 100044, China
}

Correspondence should be addressed to Xiaole Kang; darever1988@126.com

Received 28 March 2016; Revised 1 June 2016; Accepted 12 June 2016

Academic Editor: Yu Jian Cheng

Copyright (C) 2016 Zengrui Li et al. This is an open access article distributed under the Creative Commons Attribution License, which permits unrestricted use, distribution, and reproduction in any medium, provided the original work is properly cited.

The characteristics of a novel antipodal Vivaldi antenna array mounted on a dielectric cone are presented. By employing antipodal Vivaldi antenna element, the antenna array shows ultrawide bandwidth and end-fire radiation characteristics. Our simulations show that the cone curvature has an obvious influence on the performance of the conformal antenna, in terms of both the bandwidth and the radiation patterns. The thickness and permittivity of the dielectric cone have an effect on the bandwidth of the conformal antenna. Measurement results of both single antenna and conformal antenna array show a good agreement with the simulated results. The measured conformal antenna can achieve a $-10 \mathrm{~dB}\left|S_{11}\right|$ with bandwidth of $2.2-12 \mathrm{GHz}$ and demonstrate a typical endfire radiation beam. These findings provide useful guidelines and insights for the design of wideband end-fire antennas mounted on a dielectric cone.

\section{Introduction}

Wideband antennas are required for many electromagnetic applications, such as radio astronomy and UWB technology. The Vivaldi antenna, which was firstly created by Gibson in 1979 [1], has been widely used due to its simple structure, light weight, wideband, high efficiency, and high gains. In [2], a Vivaldi antenna with a parasitic meandered shaped element and a PIN diode for DVB-T and UWB applications has been presented. The PIN diode is used to switch the lower frequency band in addition to the high frequency band. Corrugation edges structure was reported in [3], which was used to reduce the width of the antenna without degrading the radiation patterns. A miniaturized antipodal Vivaldi antenna with tapered slot edge (TSE) was proposed in [4]. Compared to the regular slot edge (RSE), the TSE is able to take full use of the patch area for its coordinated shape with the antenna slot profile. A printed Vivaldi antenna with two pairs of eye-shaped slots was presented in [5]. By using the eye-shaped slots, the side lobe levels of the radiation pattern can be reduced. In this paper, a circular-shape-load antipodal Vivaldi antenna [6] with a metal director is used to study the conformal characteristics due to its small size, broad bandwidth, high gain, and stable radiation pattern.

It is well known that the conformal antennas are mainly used in aviation, radars, and military systems. For these applications, conformal antennas need to cover a wide bandwidth and have end-fire radiation beam. A variety of conformal antennas have been investigated during the past two decades, including monopole antennas $[7,8]$, slot antennas $[9,10]$, microstrip antenna arrays [11-13], log-periodic antennas [14], balanced antipodal Vivaldi antenna [15], and substrate integrated waveguide (SIW) antennas [16, 17]. However, most of these antennas are mounted on metallic surfaces and have broadside radiation beam. A few of studies about end-fire conformal antennas can be found in literatures [14-16].

The contributions of our work are as follows:

(1) The impacts of cone curvature, cone thickness, and cone permittivity on the conformal antenna's bandwidth, radiation performance are comprehensively 


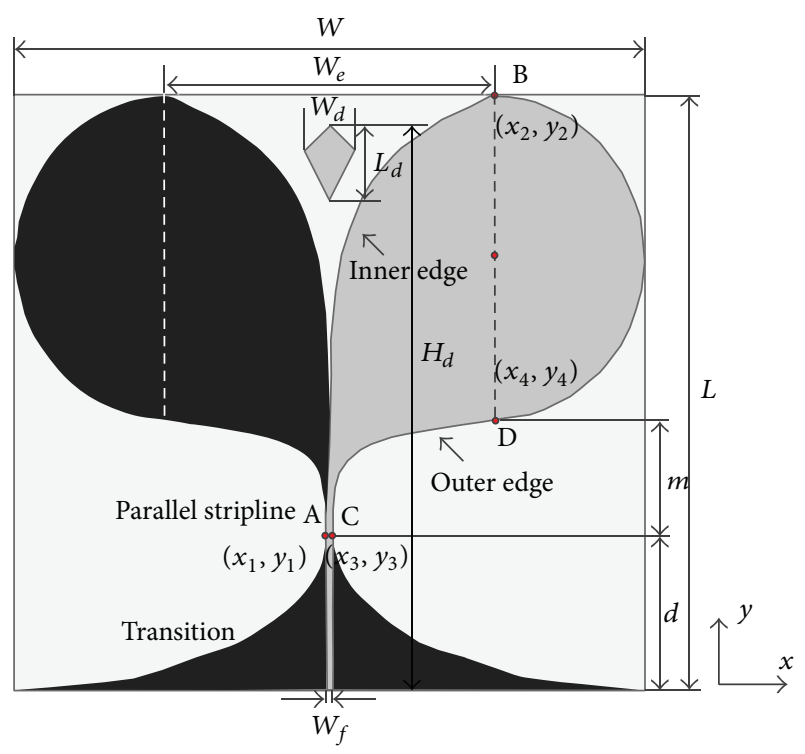

FIGURE 1: Configuration of the plane antenna element.

investigated. The antipodal Vivaldi antenna can be easily mounted on a dielectric cone. The curvature of cone has an influence on bandwidth and radiation patterns of conformal antenna. The thickness and dielectric constant of cone mainly affect the bandwidth of the conformal antenna.

(2) Measurement results with a prototype of the proposed conformal antenna array with four antenna elements are presented and compared with the simulated results.

\section{Antenna Element}

In this section, a plane antipodal Vivaldi antenna is proposed and studied, as shown in Figure 1. This antenna is printed on Teflon-F4B substrate with a dielectric constant of 3.5 and loss tangent of 0.003 . The thickness of the substrate is $0.5 \mathrm{~mm}$.

In this design of an antipodal Vivaldi antenna, two arms metalized on either side of the substrate are flared in the opposite direction to form a tapered slot. The antenna mainly consists of four parts. The first section is a quarter of elliptical taper whose minor axis is $2 \mathrm{~d}$ to achieve transition from microstrip line to parallel stripline. The second part is the parallel stripline, which is a balanced structure providing wideband transitions. The third part is a diamond-shaped metal director, which is designed to improve the gain in the upper bandwidth. The comparison of the simulated gains between the antenna with a diamond-shaped director and the one without a diamond-shaped director is plotted in Figure 2. The result shows that the gain of the antenna with a director is definitely improved in high frequency band. The last part is the radiation patch which includes two exponential curves and a half of elliptical curve. The inner edge of the tapered radiation flares satisfies the following exponential curves:

$$
x=c_{1} e^{\alpha y}+c_{2},
$$

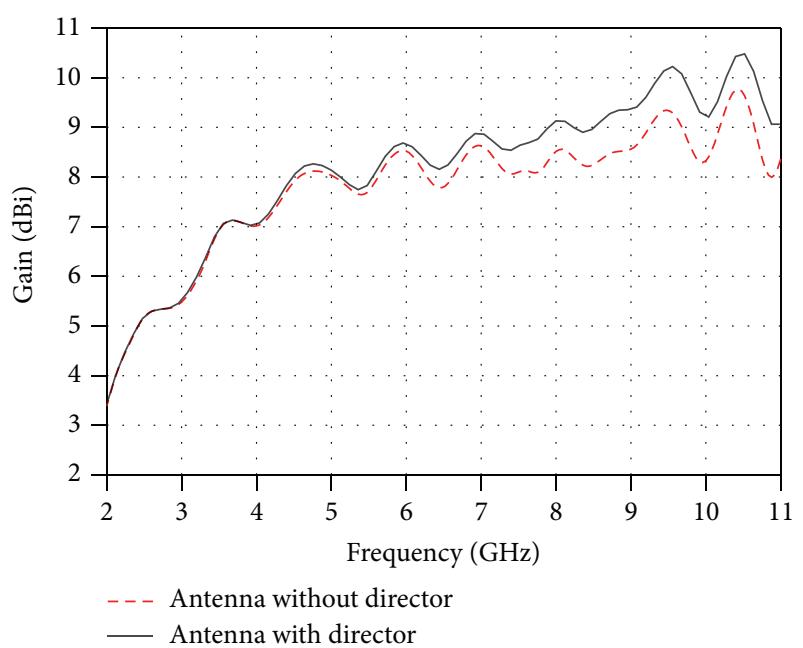

FIGURE 2: Simulated gains of plane antipodal Vivaldi antenna with and without a director.

TABLE 1: Optimized parameters of the antipodal Vivaldi antenna.

\begin{tabular}{lccccccccc}
\hline Parameters & $L$ & $W$ & $W_{e}$ & $m$ & $d$ & $W_{f}$ & $L_{d}$ & $W_{d}$ & $H_{d}$ \\
\hline Values/mm & 116 & 124 & 64 & 22.2 & 30.4 & 1.1 & 15 & 10 & 110.4 \\
\hline
\end{tabular}

where $c_{1}$ and $c_{2}$ are determined by the opening rate $\alpha$ and two points $p_{1}\left(x_{1}, y_{1}\right)$ and $p_{2}\left(x_{2}, y_{2}\right)$ :

$$
\begin{aligned}
& c_{1}=\frac{x_{2}-x_{1}}{e^{\alpha y_{2}}-e^{\alpha y_{1}}}, \\
& c_{2}=\frac{y_{1} e^{\alpha y_{2}}-y_{2} e^{\alpha y_{1}}}{e^{\alpha y_{2}}-e^{\alpha y_{1}}} .
\end{aligned}
$$

And the outer edge of the tapered radiation flares also satisfies (1), while $c_{1}$ and $c_{2}$ are determined by the opening rate $\beta$ and two points $p_{3}\left(x_{3}, y_{3}\right)$ and $p_{4}\left(x_{4}, y_{4}\right)$.

To cover the desired bandwidth $(2 \mathrm{GHz}-12 \mathrm{GHz})$, the antipodal Vivaldi antenna was simulated and optimized with the assistance of ANSYS High Frequency Structure Simulator (HFSS) Version 14. After optimization on the proposed antenna, it is fabricated with the parameters indicated in Table 1. Some of the parameters are specified as follows: $\alpha=$ 0.0785 and $\beta=0.3$.

The prototype of the antipodal Vivaldi antenna is shown in Figure 3. It was measured by an Agilent E5071C Vector Network Analyzer in an anechoic chamber in Communication University of China.

Figure 4 shows the comparisons of $\left|S_{11}\right|$ between the simulated and measured results of the plane antipodal Vivaldi antenna. It is found that the measured results show a reasonable agreement with the simulation results over the frequency band $\left(\left|S_{11}\right| \leq-10 \mathrm{~dB}\right)$ between $2.36 \mathrm{GHz}$ and $12 \mathrm{GHz}$. The small deviation of the two results may be caused by the imperfection of hand-soldering of the SMA connector.

The far field radiation patterns in the $E$-plane ( $x o y$ plane) and $H$-plane ( $y o z$ plane) at different frequencies were measured and shown in Figure 5. The measured copolarization 


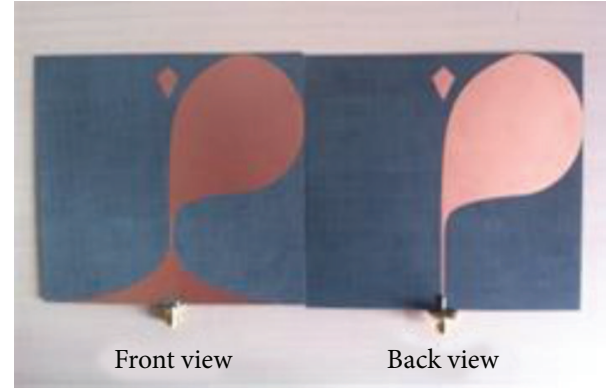

Figure 3: Prototype of the proposed antenna.

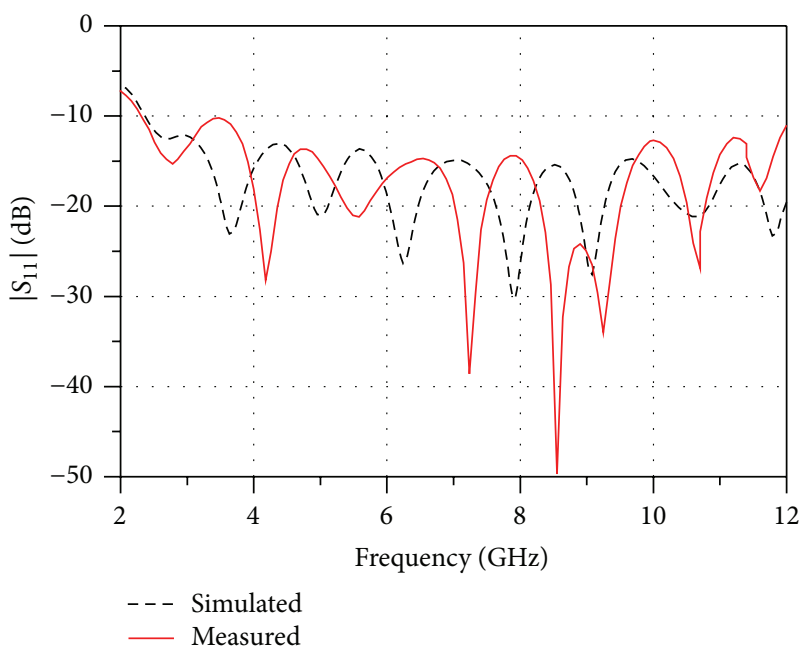

FIgURE 4: Measured and simulated $\left|S_{11}\right|$ of the plane antipodal Vivaldi antenna.

radiation patterns and the simulated results show a good agreement in both planes. However, the measured crosspolarization radiation patterns are larger than the simulated results. It may be caused by the deviation of the relative position between test antenna and reference antenna. The proposed antenna has good unidirectional radiation patterns and the main lobes are fixed in the end-fire direction ( $y$-axis direction) within the effective bandwidth.

The measured front-to-back ratios of the antipodal Vivaldi antenna are listed in Table 2. According to Table 2, the front-to-back ratios of the antenna achieve more than $12 \mathrm{~dB}$ except for a few of frequency points, which confirmed the end-fire characteristic of the antenna. Within the operating frequency band, the simulated and measured gain of the antenna in end-fire direction vary between $2.5 \mathrm{dBi}$ and $9.8 \mathrm{dBi}$, as shown in Figure 6.

Since the linear phase response of the antenna in the time domain is one of the most important parameters in wideband systems, the group delay of two antipodal Vivaldi antennas with a distance of $30 \mathrm{~cm}$ has also been measured. Figure 7 shows the variation of the group delay less than $5 \mathrm{~ns}$ within the desired frequency bands, which indicates that the phase of the antenna shifts little within the operating frequency band.
TABLE 2: Measured front-to-back ratio of the proposed antenna.

\begin{tabular}{lcccc}
\hline Frequency $(\mathrm{GHz})$ & 2 & 4 & 6 & 8 \\
\hline E-plane $(\mathrm{dB})$ & 6 & 12 & 13 & 13 \\
$H$-plane $(\mathrm{dB})$ & 12 & 13 & 16 & 15 \\
\hline
\end{tabular}

TABLE 3: Simulated half power beam-width of the antipodal Vivaldi antenna mounted on different cones.

\begin{tabular}{lcccccccccc}
\hline Frequency $(\mathrm{GHz})$ & 2 & 3 & 4 & 5 & 6 & 7 & 8 & 9 & 10 & 11 \\
\hline E-plane (deg) & 62 & 56 & 48 & 40 & 40 & 54 & 50 & 50 & 50 & 40 \\
$H$-plane (deg) & 116 & 106 & 76 & 60 & 56 & 50 & 54 & 58 & 56 & 56 \\
\hline
\end{tabular}

Thus, the proposed antenna achieves a desirable time domain characteristic.

\section{Conformal Antenna Performances}

3.1. Effects of Cone Curvature. The proposed antipodal Vivaldi antenna is mounted on a dielectric cone to investigate the conformal antenna characteristics. The antenna is on dielectric cones with different curvatures, as shown in Figure 8 . The outer diameters of the three cones' top and bottom surfaces are $300 / 360 \mathrm{~mm}, 190 / 210 \mathrm{~mm}$, and $130 / 150 \mathrm{~mm}$, respectively. The height, thickness, and dielectric constant are $350 \mathrm{~mm}, 0.5 \mathrm{~mm}$, and 2.1 for all three cones.

Figure 9 shows the simulated voltage standing wave ratio (VSWR) of the conformal antenna with different curvatures. It can be observed that, with the increasing of cone curvature, the VSWR deteriorates especially in the low and middle frequency bands. The simulated radiation patterns of the conformal antenna with different cones curvatures at $2 \mathrm{GHz}$, $4 \mathrm{GHz}, 6 \mathrm{GHz}$, and $8 \mathrm{GHz}$ are plotted in Figure 10. It is shown that the variation of cone curvature has little effects on the copolarization radiation patterns of the conformal antenna. Since the antenna is bent on the cone, there exists an extra electric current component in $-Z$ direction. Therefore, the cross-polarization of the conformal antenna becomes larger with the increasing of cone curvature. Besides, to illustrate the impacts of cone curvature on radiation pattern between planar Vivaldi antenna and curved surface antenna, which is bent on a cone with the diameters of $190 / 210 \mathrm{~mm}$, the simulated radiation pattern at $4 \mathrm{GHz}$ is given in Figure 11 . It is observed that the cross-polarization of the conformal antenna is larger than the planar antenna. The simulated half power beam-width of the conformal antenna is less than 116 degrees as shown in Table 3.

3.2. Effects of Cone Thickness. In this subsection, the antipodal Vivaldi antenna is mounted on cones with different thickness $(5 \mathrm{~mm}, 7 \mathrm{~mm}$, and $10 \mathrm{~mm})$ so as to examine the effect of the cone thickness on the characteristics of the conformal antenna. The outer diameters of the cones' top and bottom surfaces are 190 and $210 \mathrm{~mm}$, respectively. The height and dielectric constant of cones are $350 \mathrm{~mm}$ and 2.1, respectively. 

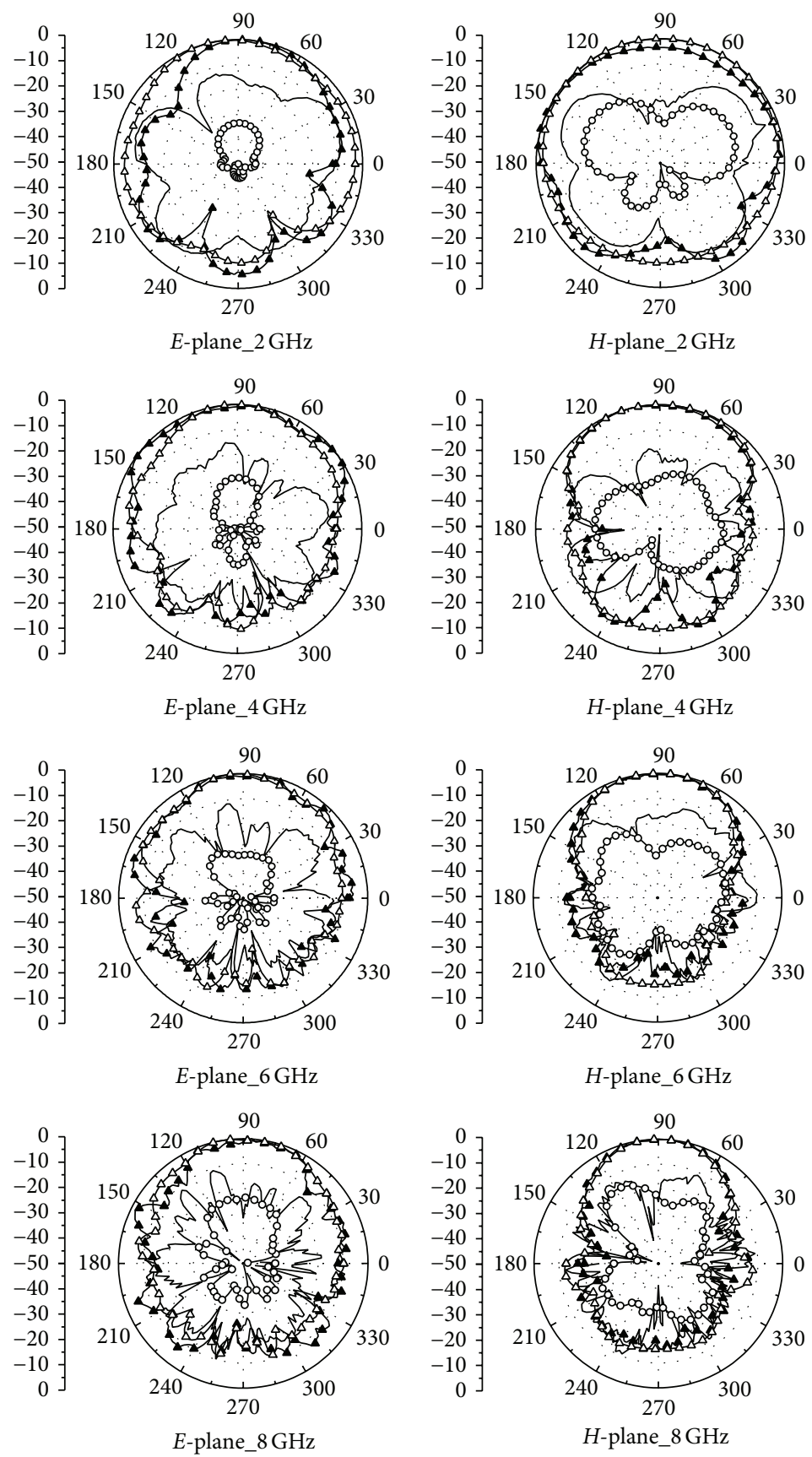

Figure 5: Measured and simulated radiation patterns of the antipodal Vivaldi antenna. - $\mathbf{\Delta}$ - measured copolarization, - measured crosspolarization, $-\triangle$ - simulated copolarization, and -O- simulated cross-polarization.

Figure 12 presents the simulated VSWR of conformal antenna with different cone thickness. It is found that as the thickness increases, the VSWR becomes larger in the lower frequency band. The VSWR varies between 1 and 3 in the whole operating band. Figure 13 shows the radiation patterns with different cone thickness at $7 \mathrm{GHz}$. The gain variation with different cone thicknesses for the conformal antenna is demonstrated in Figure 14. It turned out that, with the increasing cone thickness, the gain has obvious decreases in the middle frequency band due to the enlargement of the cross-polarization.

3.3. Effects of Cone Dielectric Constants. We studied the performance of the antenna mounted on cones with different dielectric constants of 2.1, 2.7, and 4.4, respectively. The outer diameters of the cones' top and bottom surfaces are 190 and $210 \mathrm{~mm}$. The height and thickness of cones are $350 \mathrm{~mm}$ and $5 \mathrm{~mm}$. 


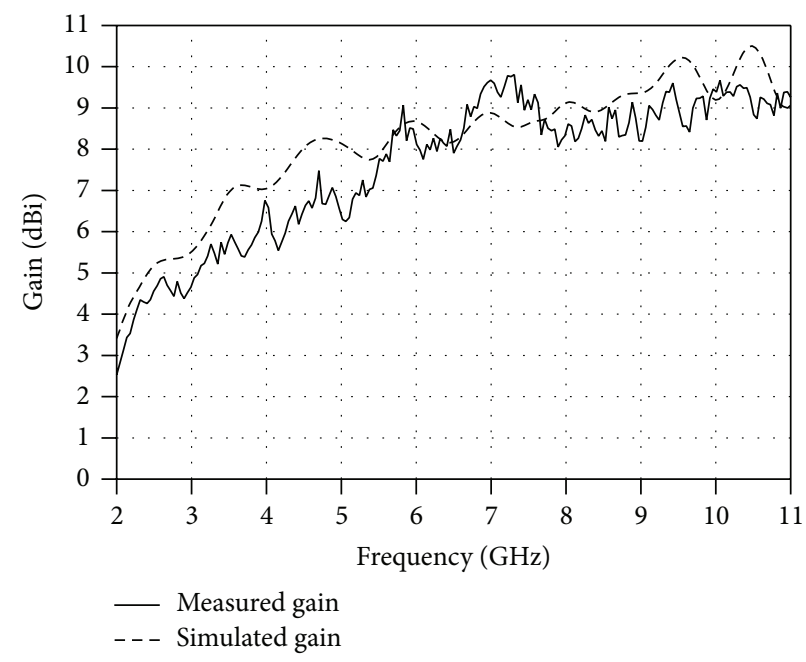

FIGURE 6: Measured and simulated gain of the plane antipodal Vivaldi antenna.

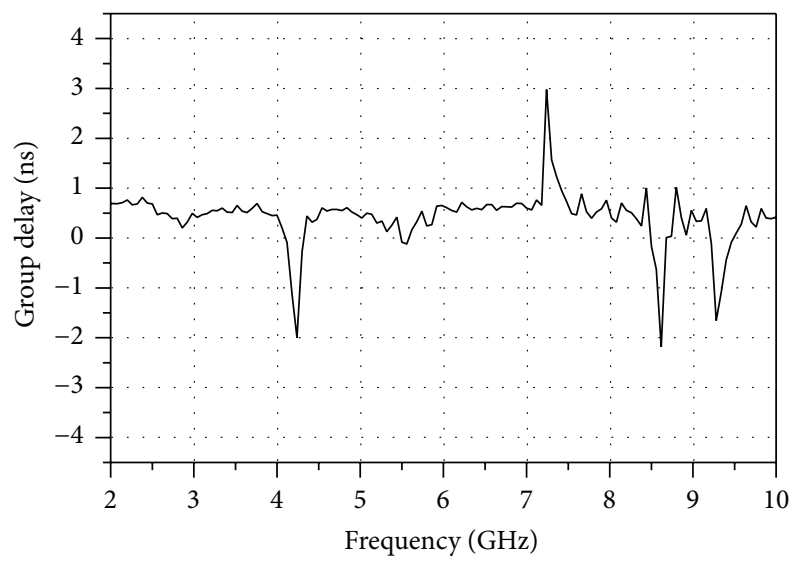

FIGURE 7: Measured group delay of the proposed antenna.

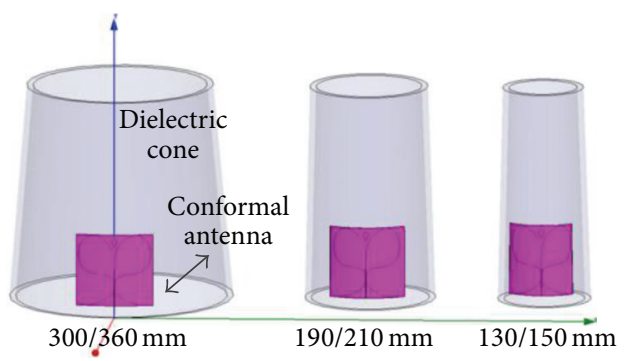

FIGURE 8: Configuration of the proposed antenna mounted on cones with different curvatures.

Figure 15 shows that the cone dielectric constant has an effect on VSWR of conformal antenna. It is found that with the increasing of the dielectric constant, the VSWR deteriorates at the low frequency band. Radiation patterns with different cone dielectric constants at $8 \mathrm{GHz}$ are shown in Figure 16. It is shown that the cross-polarization become

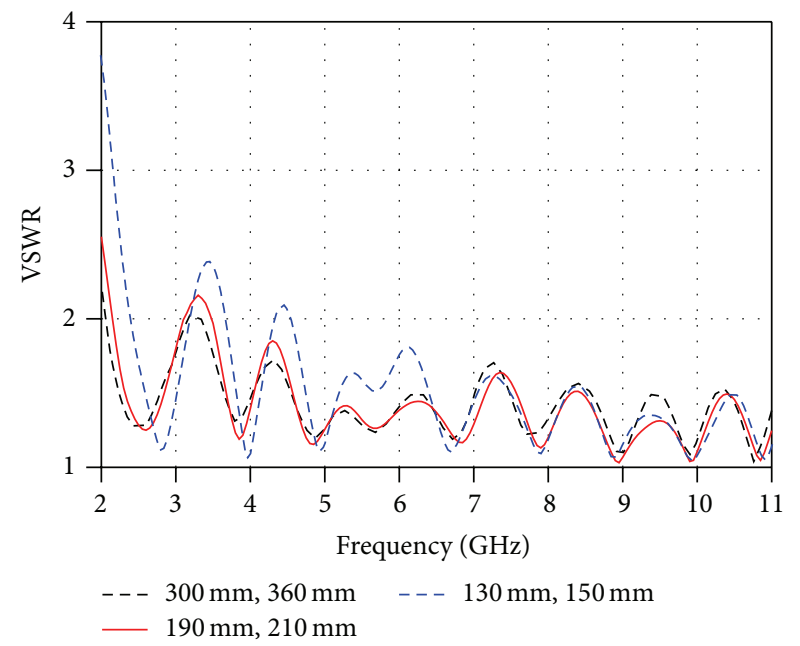

FIGURE 9: Simulated VSWR of conformal antenna with different cone curvatures.

larger with the increased dielectric constant. Figure 17 illustrates the gain variation of the conformal antenna with different dielectric constants. With respect to the enlargement of cross-polarization, the gain decreases dramatically in high frequency bandwidth.

\section{Experimental Results}

A prototype of conformal antenna array is built by mounting four proposed antennas on the surface of a polypropylene cone with a dielectric constant of 2.3, as shown in Figure 18. The height, thickness, and top and bottom surfaces' outer diameter of the cone are $274 \mathrm{~mm}, 3 \mathrm{~mm}$, and $188 / 204 \mathrm{~mm}$, respectively. The prototype was measured by an Agilent E5071C Vector Network Analyzer in an anechoic chamber in CUC. 

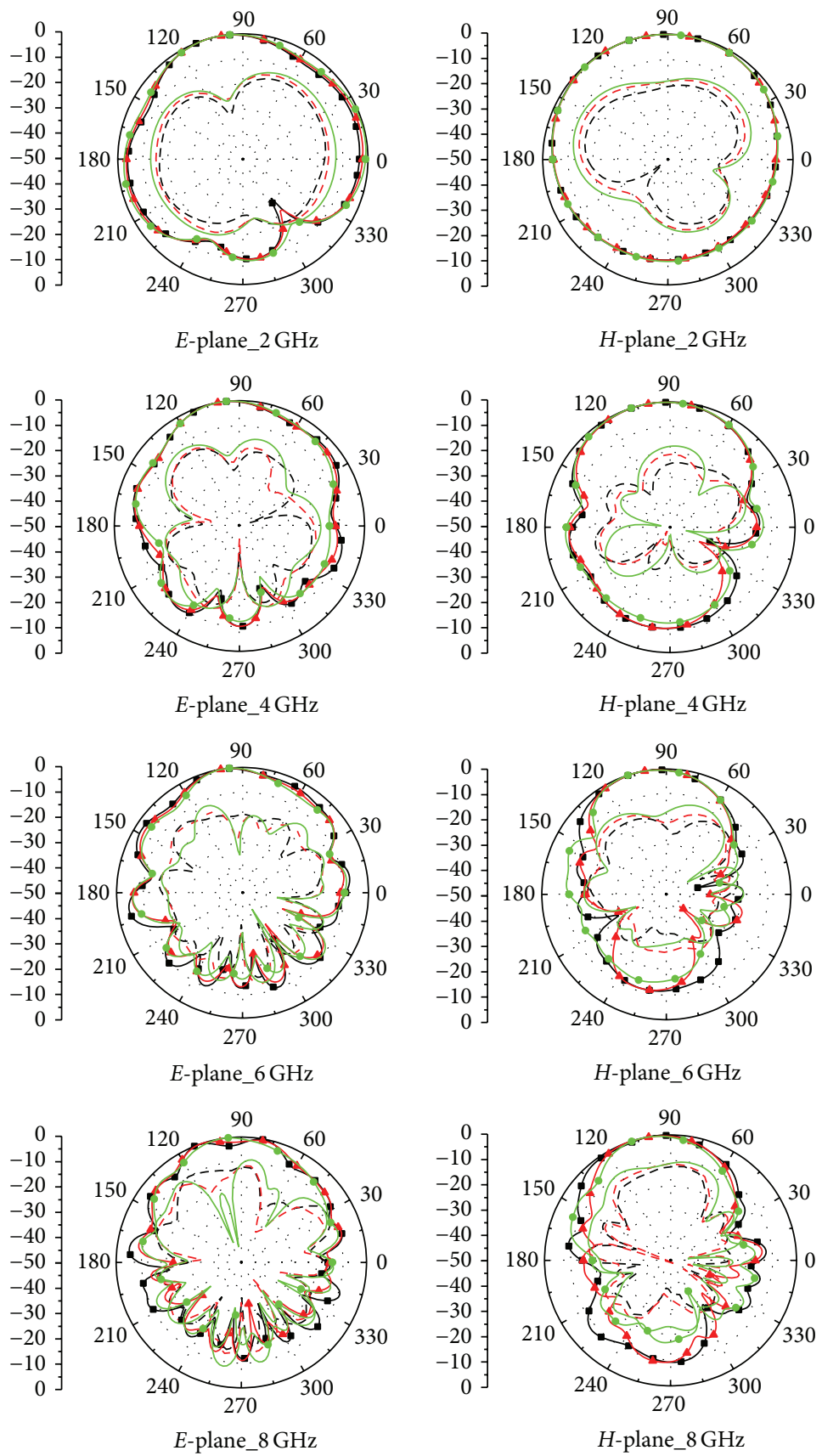

FIGURE 10: Simulated radiation patterns of conformal antenna with different cone curvatures. - - - copolarization (300/360 mm), (the black dash lines) cross-polarization $(300 / 360 \mathrm{~mm})$, - $\mathbf{\Delta}$ - copolarization $(190 / 210 \mathrm{~mm})$, (the red dash lines) cross-polarization $(190 / 210 \mathrm{~mm})$, copolarization $(130 / 150 \mathrm{~mm})$, and - cross-polarization $(130 / 150 \mathrm{~mm})$.

The measured and simulated $\left|S_{11}\right|$ of the proposed antipodal Vivaldi antenna are shown in Figure 19. Good impedance matching with the $50 \Omega$ coaxial line is achieved, which satisfies the required operating frequency band from $2.2 \mathrm{GHz}$ to $12 \mathrm{GHz}$.

Figure 20 shows the measured and simulated radiation patterns of the conformal antenna in both E-plane (xoy plane) and $H$-plane (yoz plane) at $2 \mathrm{GHz}, 4 \mathrm{GHz}, 6 \mathrm{GHz}$, $8 \mathrm{GHz}$, and $10 \mathrm{GHz}$. It is found that the conformal antenna has end-fire radiation beams in both planes. Figure 21 shows the comparisons of the simulated and measured gain of the conformal antipodal Vivaldi antenna. The measured radiation patterns and gain both show good agreements with the simulated results. The isolation between the adjacent ports of the conformal antenna is also investigated. It can be observed in Figure 22 that the measured result is less than $-25 \mathrm{~dB}$ in the operating frequency bands, which is good for the port isolation of the conformal antenna. 

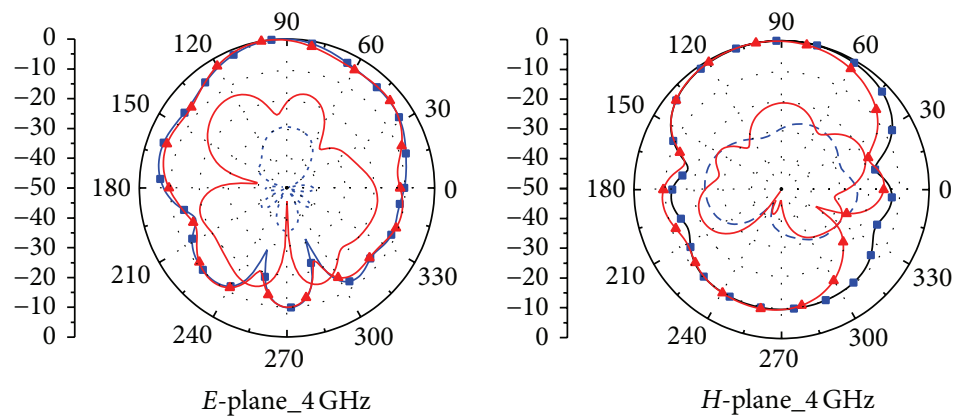

FIGURE 11: Simulated radiation patterns of plane antenna and conformal antenna. - $\mathbf{-}$ - copolarization (plane), --- cross-polarization (plane), - $\Delta$ - copolarization (conformal), and - cross-polarization (conformal).

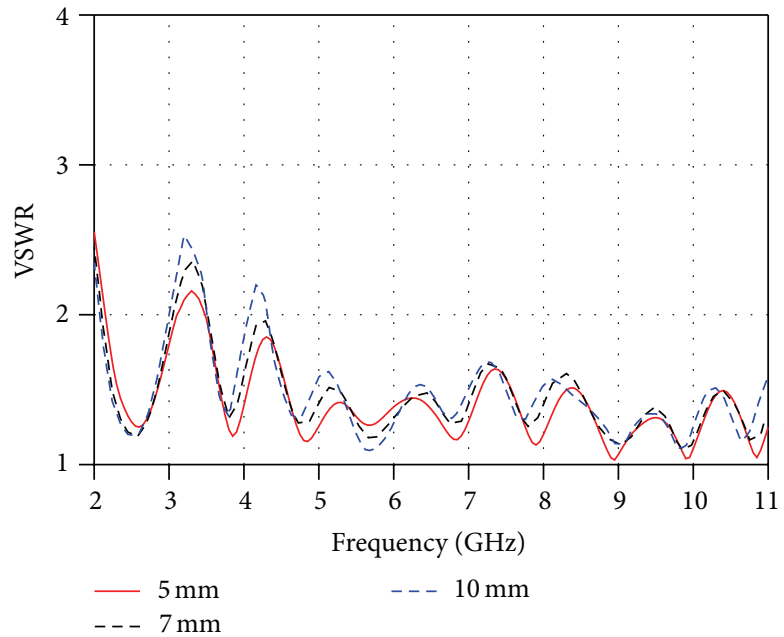

FIGURE 12: Simulated VSWR of conformal antenna with different cone thickness.
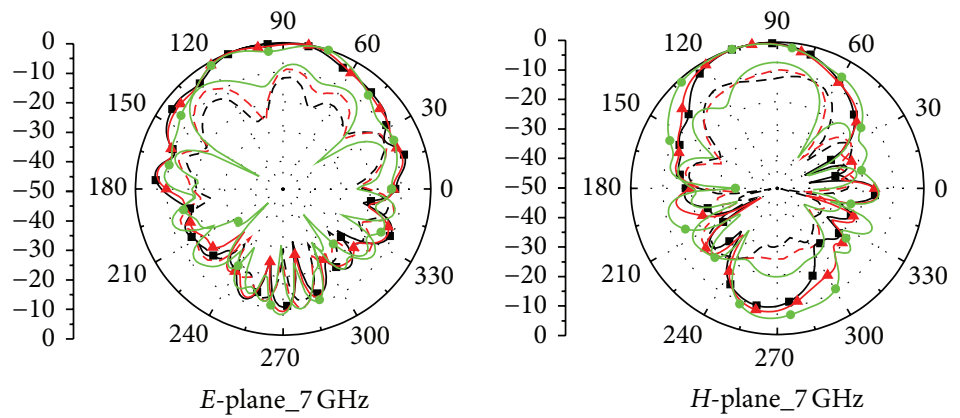

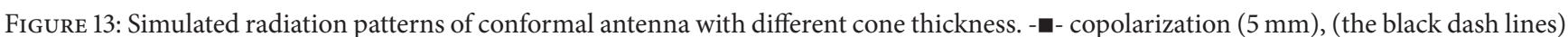
cross-polarization $(5 \mathrm{~mm})$, - $\mathbf{\Lambda}$ - copolarization $(7 \mathrm{~mm})$, (the red dash lines) cross-polarization $(7 \mathrm{~mm})$, - - copolarization $(10 \mathrm{~mm})$, and cross-polarization $(10 \mathrm{~mm})$.

\section{Conclusion}

This paper presented a novel wideband end-fire conformal antenna array mounted on a dielectric cone. The effects of the cone curvature, thickness, and dielectric constant on the performance of the conformal antenna are thoroughly investigated and some inspiring results for end-fire conformal antenna design have been obtained. Measured and simulated results of the prototype show the conformal antenna has wide frequency bands, end-fire radiation patterns, and wide half power beam-width. The proposed antenna array has a great potential to be used in conformal systems such as missiles, radars, and aircrafts.

\section{Competing Interests}

The authors declare that there is no conflict of interests regarding the publication of this paper. 


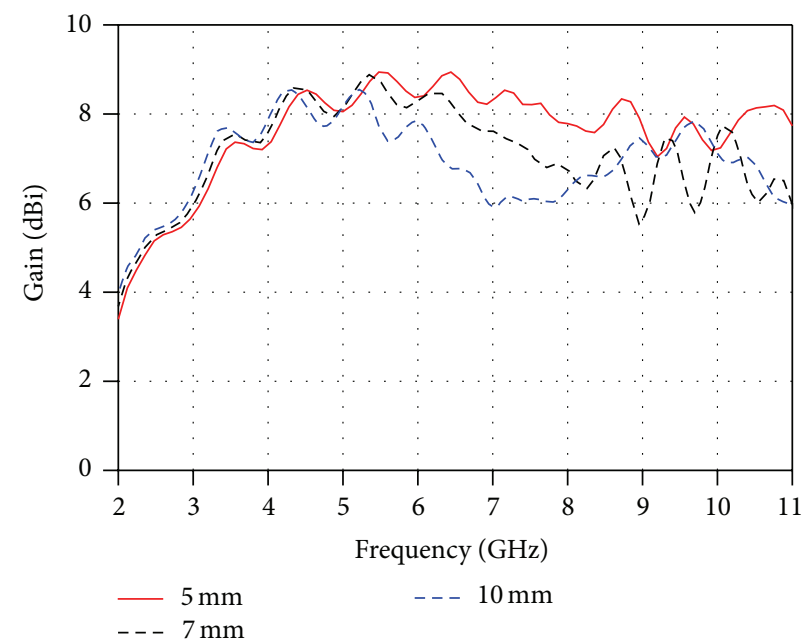

FIGURE 14: Simulated gain of conformal antenna with different cone thickness.

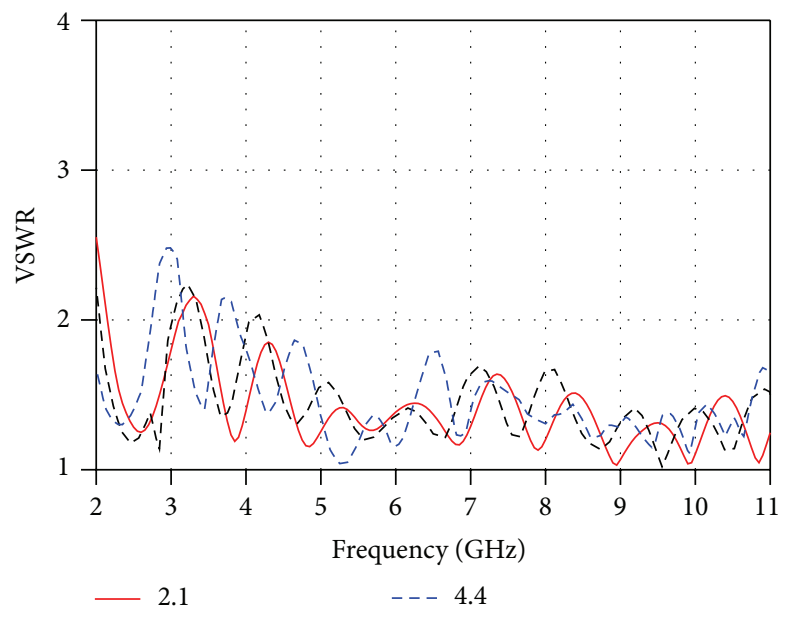

FIGURE 15: Simulated VSWR of conformal antenna with different dielectric constants.
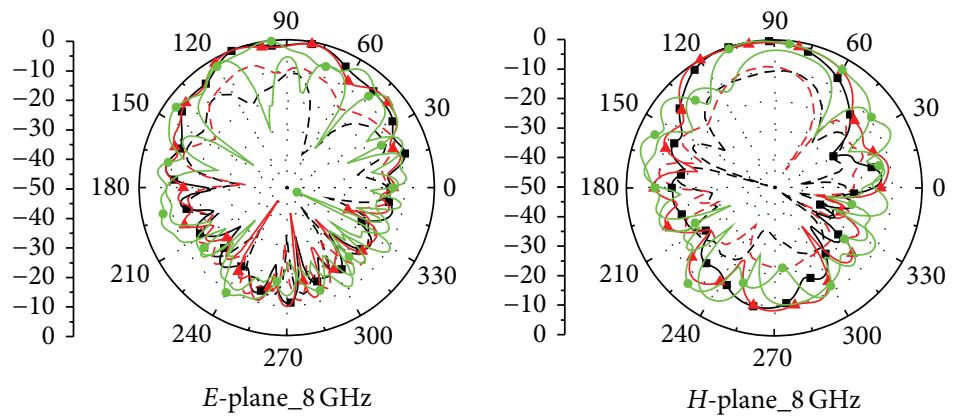

FIGURE 16: Simulated radiation patterns of conformal antenna with different dielectric constants. - - copolarization (2.1), (the black dash lines) cross-polarization (2.1), - $\mathbf{\Lambda}$ - copolarization (2.7), (the red dash lines) cross-polarization (2.7), - $\bullet$ - copolarization (4.4), and - crosspolarization (4.4). 


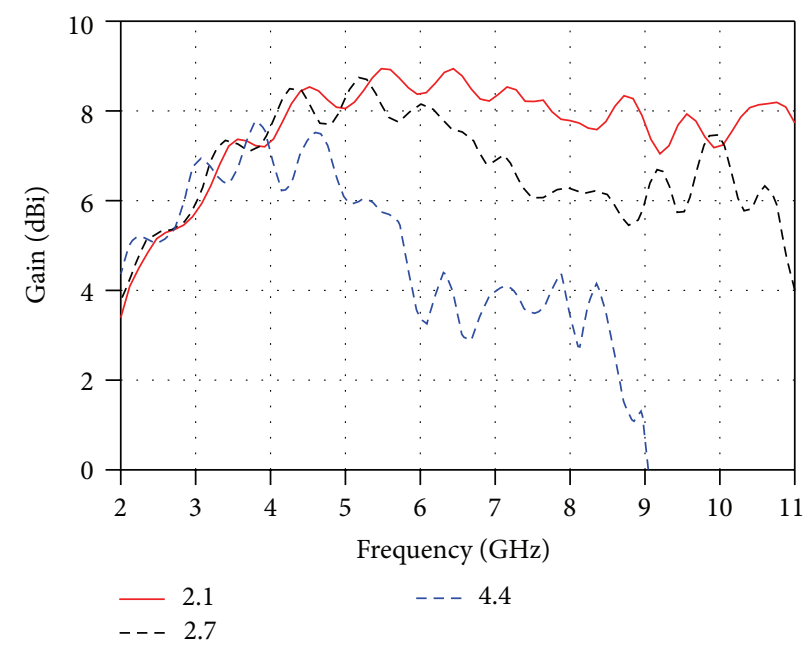

FIGURE 17: Simulated gain of conformal antenna with different dielectric constants.

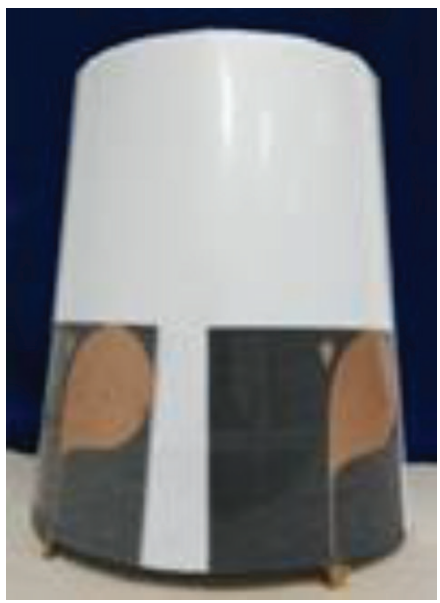

FIGURE 18: Prototype of four antipodal Vivaldi antennas mounted on a dielectric cone.

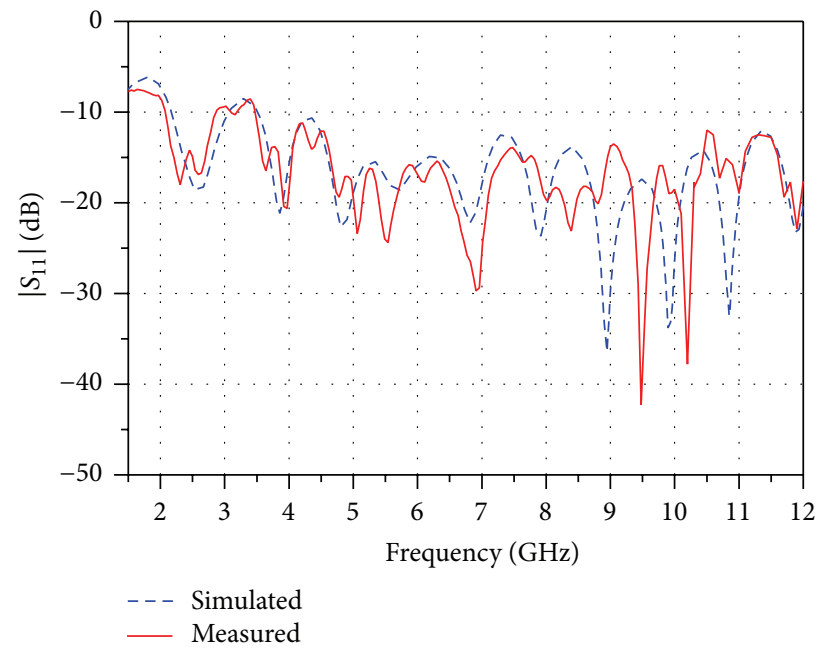

Figure 19: Measured and simulated $\left|S_{11}\right|$ of the conformal antenna. 

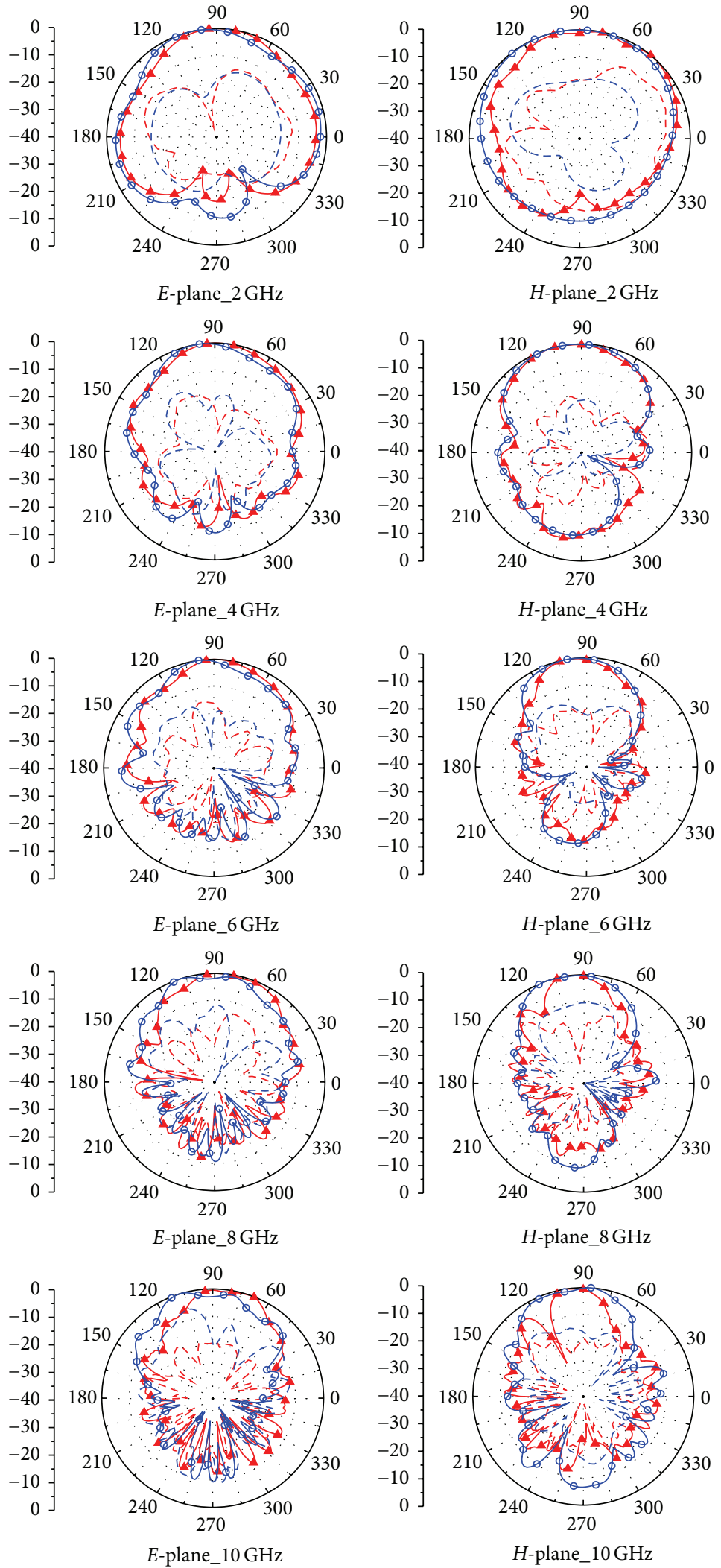

Figure 20: Measured and simulated radiation patterns of conformal antenna. -O- simulated copolarization, (the blue dash lines) simulated cross-polarization, - $\mathbf{\Delta -}$ - measured copolarization, and (the red dash lines) measured cross-polarization. 


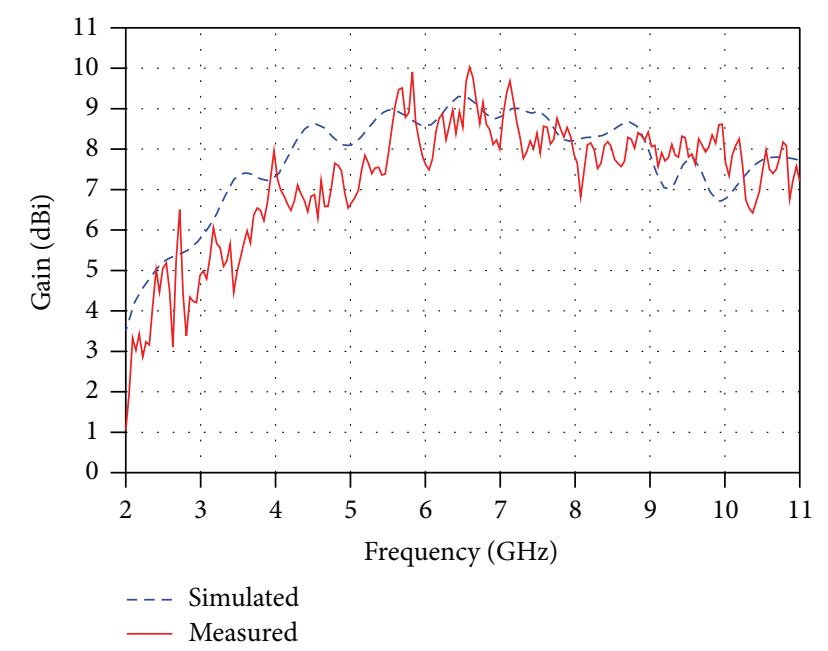

FIGURE 21: Measured and simulated gain of the conformal antenna.

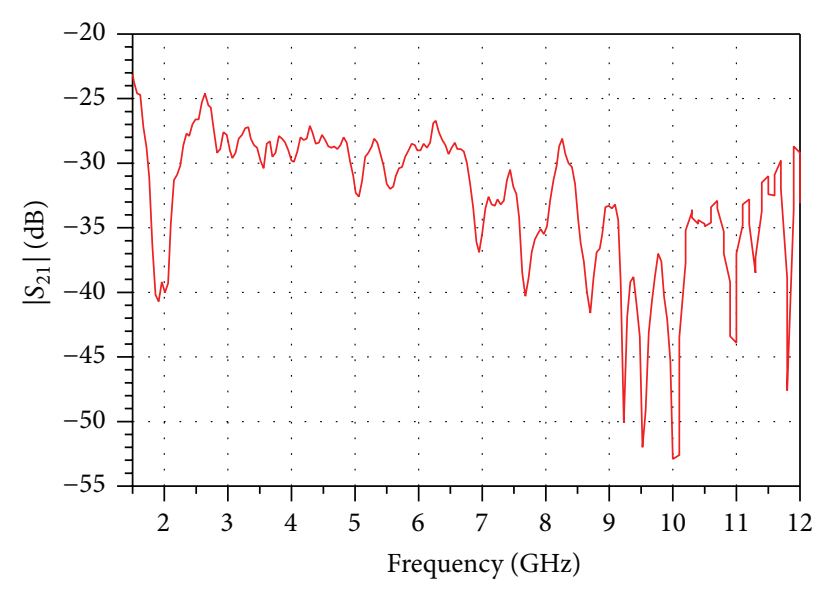

FIGURE 22: Measured isolation of the conformal antenna.

\section{Acknowledgments}

This work was supported in part by the Major Program of the National Natural Science Foundation of China (NSFC) under Grant no. 61331002, in part by Excellent Innovation Team of CUC under Grant no. yxtd201303, and in part by CUC scientific research project under Grant no. 3132016XNG1604.

\section{References}

[1] P. J. Gibson, "The Vivaldi aerial," in Proceedings of the 9th European Microwave Conference, pp. 101-105, Brighton, UK, September 1979.

[2] D. M. Elsheakh and E. A. Abdallah, "Ultrawideband Vivaldi antenna for DVB-T, WLAN, and WiMAX applications," International Journal of Antennas and Propagation, vol. 2014, Article ID 761634, 7 pages, 2014.

[3] P. Fei, Y.-C. Jiao, W. Hu, and F.-S. Zhang, "A miniaturized antipodal vivaldi antenna with improved radiation characteristics," IEEE Antennas and Wireless Propagation Letters, vol. 10, pp. 127-130, 2011.
[4] C. Deng and Y.-J. Xie, "Design of resistive loading Vivaldi antenna," IEEE Antennas and Wireless Propagation Letters, vol. 8, pp. 240-243, 2009.

[5] K. Ma, Z. Q. Zhao, J. N. Wu, M. S. Ellis, and Z. P. Nie, "A printed vivaldi antenna with improved radiation patterns by using two pairs of eye-shaped slots for UWB applications," Progress in Electromagnetics Research, vol. 148, pp. 63-71, 2014.

[6] J. Bai, S. Y. Shi, and D. W. Prather, "Modified compact antipodal vivaldi antenna for 4-50 GHz UWB application," IEEE Transactions on Antennas and Propagation, vol. 59, no. 4, pp. 1051-1057, 2011.

[7] H.-Y. Liang, H.-C. Yang, and J. Zhang, "A cylindrical conformal directional monopole antenna for borehole radar application," IEEE Antennas and Wireless Propagation Letters, vol. 11, pp. 1525-1528, 2012.

[8] Z.-Q. Liu, Y.-S. Zhang, Z. P. Qian, Z. P. Han, and W. M. Ni, "A novel broad beamwidth conformal antenna on unmanned aerial vehicle," IEEE Antennas and Wireless Propagation Letters, vol. 11, pp. 196-199, 2012.

[9] S. Nikolaou, G. E. Ponchak, J. Papapolymerou, and M. M. Tentzeris, "Conformal double exponentially tapered slot antenna (DETSA) on LCP for UWB applications," IEEE Transactions on Antennas and Propagation, vol. 54, no. 6, pp. $1663-$ 1669, 2006.

[10] G. E. Ponchak, J. L. Jordan, and C. T. Chevalier, "Characteristics of Double Exponentially Tapered Slot Antenna (DETSA) conformed in the longitudinal direction around a cylinder," IEEE Antennas and Wireless Propagation Letters, vol. 6, pp. 60-63, 2007.

[11] B. D. Braaten, S. Roy, S. Nariyal et al., "A self-adapting flexible (SELFLEX) antenna array for changing conformal surface applications," IEEE Transactions on Antennas and Propagation, vol. 61, no. 2, pp. 655-665, 2013.

[12] K. Wincza, S. Gruszczynski, and K. Sachse, "Conformal fourbeam antenna arrays with reduced sidelobes," Electronics Letters, vol. 44, no. 3, pp. 174-175, 2008.

[13] P. Knott, T. Bertuch, H. Wilden, O. Peters, A. R. Brenner, and I. Walterscheid, "SAR Experiments using a conformal antenna array radar demonstrator," International Journal of Antennas and Propagation, vol. 2012, Article ID 142542, 7 pages, 2012.

[14] X. Gao, Z. Shen, and C. Z. Hua, "Conformal VHF logperiodic balloon antenna," IEEE Transactions on Antennas and Propagation, vol. 63, no. 6, pp. 2756-2761, 2015.

[15] P. Wang, G. J. Wen, H. B. Zhang, and Y. H. Sun, "A wideband conformal end-fire antenna array mounted on a large conducting cylinder," IEEE Transactions on Antennas and Propagation, vol. 61, no. 9, pp. 4857-4861, 2013.

[16] Y. Zhao, Z. X. Shen, and W. Wu, "Conformal SIW H-plane horn antenna on a conducting cylinder," IEEE Antennas and Wireless Propagation Letters, vol. 14, pp. 1271-1274, 2015.

[17] Y. J. Cheng, H. Xu, D. Ma, J. Wu, L. Wang, and Y. Fan, "Millimeter-wave shaped-beam substrate integrated conformal array antenna," IEEE Transactions on Antennas and Propagation, vol. 61, no. 9, pp. 4558-4566, 2013. 


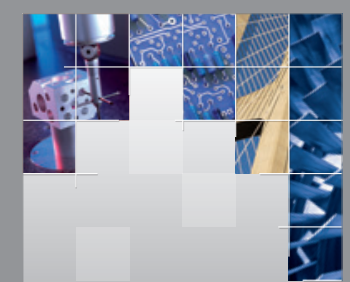

\section{Enfincering}
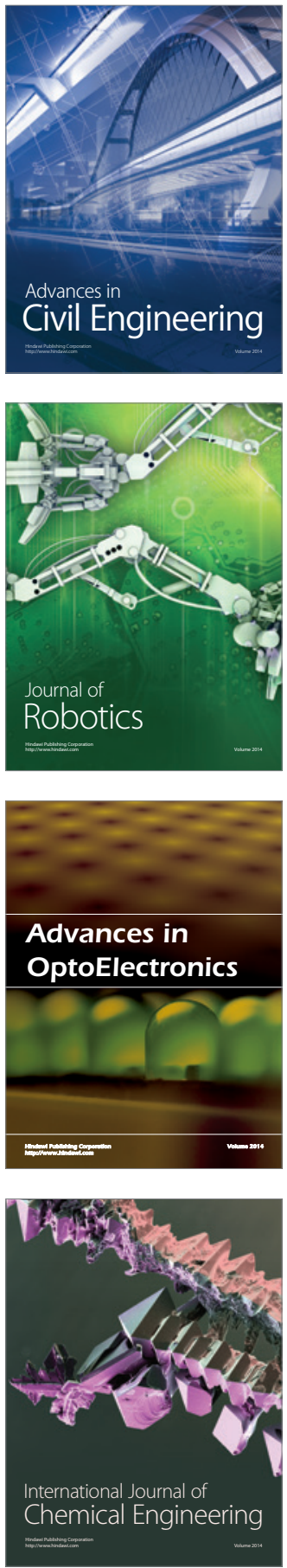

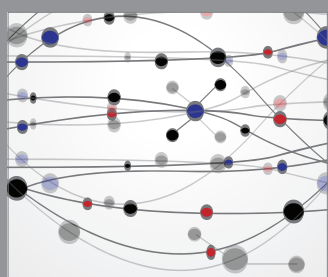

The Scientific World Journal

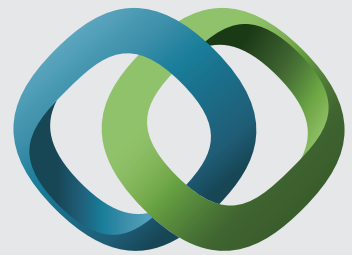

\section{Hindawi}

Submit your manuscripts at

http://www.hindawi.com
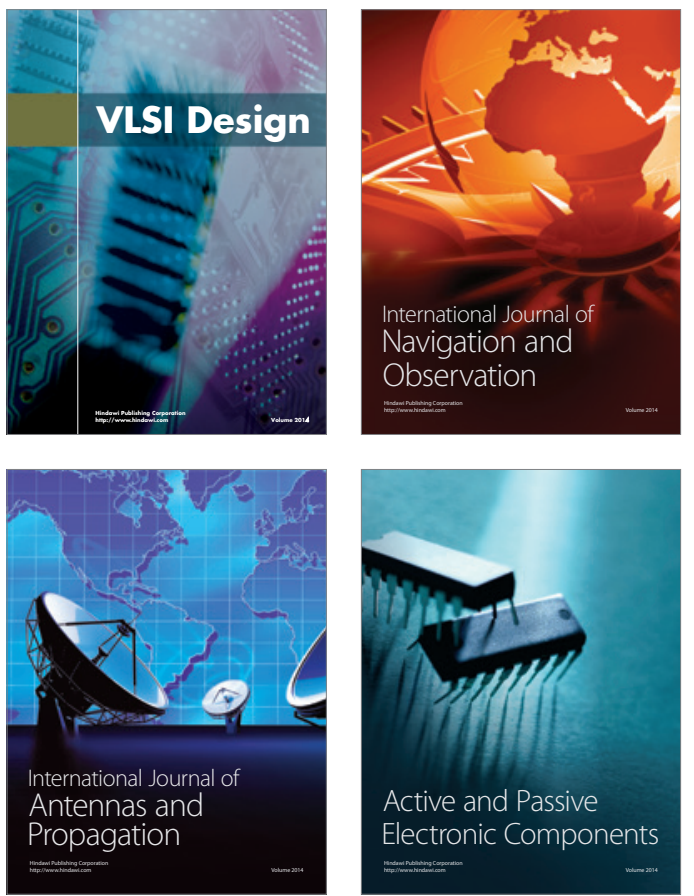
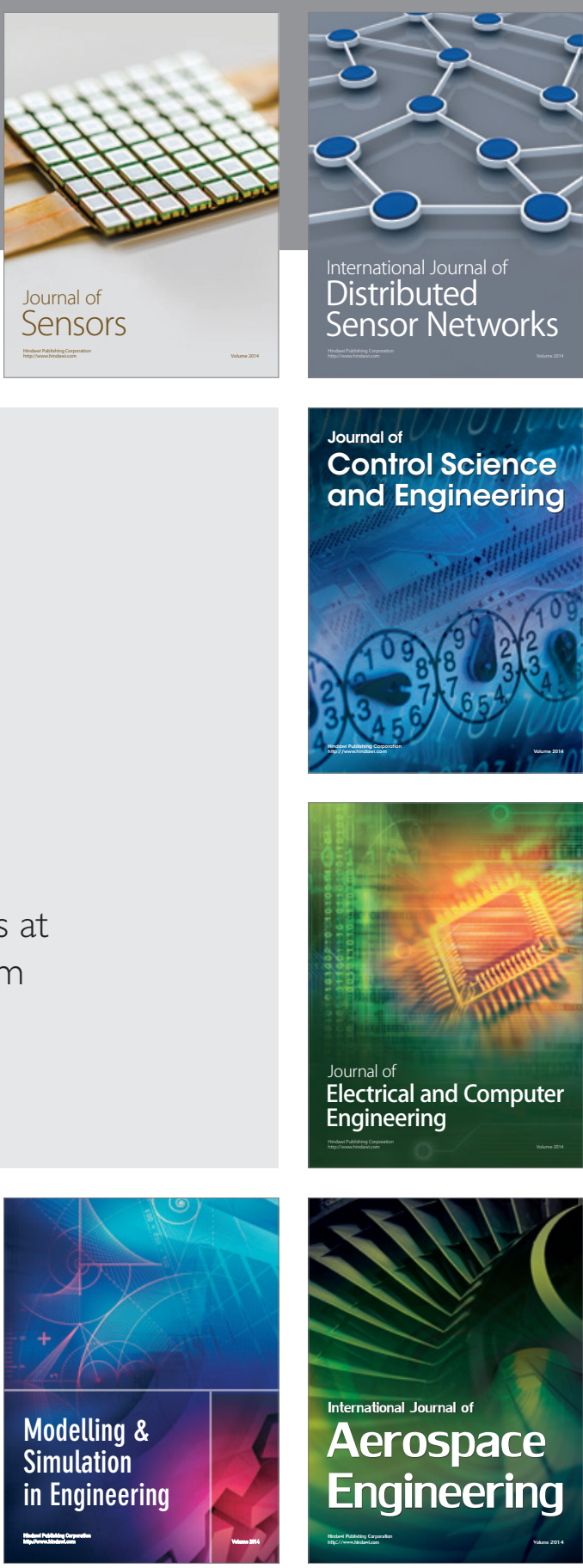

International Journal of

Distributed

Sensor Networks

Journal of

Control Science

and Engineering
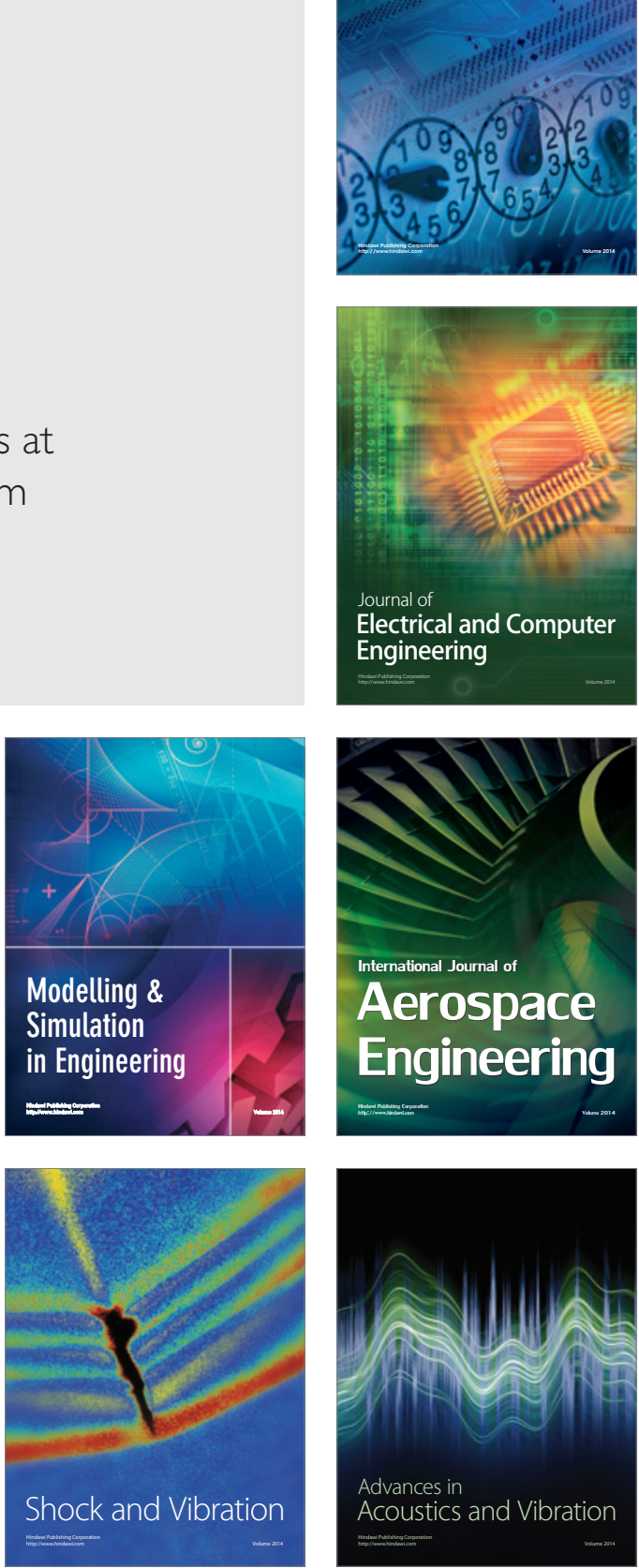